\title{
Tendências das políticas de inovação da OCDE
}

\author{
Luciano Martins Costa Póvoa*
}

RESUMO - A OCDE lançou recentemente novas diretrizes para as políticas de inovação que representam um passo importante no reconhecimento de que a inovação não é apenas um fator importante para o crescimento econômico, mas também definidor dos rumos do futuro da economia e da solução de problemas globais. Neste artigo são apresentadas, brevemente, essas diretrizes e apontadas algumas das principais tendências para as políticas de inovação.

Palavras-chave: Inovação. Políticas de inovação. Mudanças institucionais.

\section{INTRODUÇÃO}

Este breve artigo tem como objetivo apresentar as políticas de inovação recomendadas pela Organização para a Cooperação e Desenvolvimento Econômico (OCDE), de maneira a apontar as tendências para o início do século XXI. As propostas elaboradas pela OCDE ao longo das últimas quatro décadas têm influenciado de forma significativa, mesmo que indiretamente, as políticas de vários países. Assim, é importante avaliar a pertinência de tais políticas para o Brasil.

Desde 1963, a OCDE tem lançado, no início de cada década, diretrizes de políticas de ciência, tecnologia e inovação elaboradas por um grupo de especialistas. Tais diretrizes nem sempre são adotadas pelos países membros, mas constituem a principal fonte de difusão de novas ideias e abordagens para o entendimento dos mecanismos fundamentais dos avanços da ciência e da tecnologia e dos desafios para a geração de inovações.

O relatório mais recente da OCDE destaca que as políticas de inovação não significam necessariamente o aporte de mais recursos públicos. Podem ser implantadas na forma de mudanças institucionais que proporcionem um melhor ambiente social e econômico para a transformação de ideias em produtos.

\section{POLÍTICAS DE INOVAÇÃO}

Até meados da década de 1990, as políticas de inovação eram associadas às de tecnologia. Por exemplo, estímulos fiscais ou financiamentos dos gastos com P\&D eram tidos como políticas de "tecnologia e inovação".

Contudo, o maior entendimento da inovação como um processo não só de geração

\footnotetext{
* Doutor em Economia pela Universidade Federal de Minas Gerais. É professor adjunto do Departamento de Economia da Universidade de Brasília. Endereço eletrônico: lpovoa@unb.br.
} 
de novos produtos e processos, mas também como os desafios de sua introdução no mercado têm feito governos de vários países adotarem uma nova perspectiva de política de inovação que enfatiza a interação entre os agentes envolvidos no processo como um todo. Essas novas tendências serão discutidas a seguir.

\subsection{INDICADORES}

Os indicadores de inovação são recentes. Os primeiros grandes estudos nacionais foram conduzidos na Europa na década de 1990 e o aperfeiçoamento levou à elaboração de diretrizes, como o Manual de Oslo, que são amplamente seguidas por vários países.

A Tabela 1 apresenta a taxa de inovação em países europeus e no Brasil. Os dados para a Europa são baseados no Community Innovation Survey - CIS 2006, que compreende dados referentes ao período 2004-2006. Os dados para o Brasil são da Pesquisa de Inovação Tecnológica - PINTEC 2005, que abrange o período 2003-2005 . Por serem baseados no Manual de Oslo é possível fazer comparações simples entre alguns resultados das pesquisas realizadas no Brasil e em países europeus.

A Alemanha se destaca por ter o maior percentual de empresas que realizaram algum tipo de inovação no período considerado (62,6\%), enquanto a média europeia é de 39\%. Em apenas quatro países a taxa de inovação supera 50\% (Alemanha, Bélgica, Finlândia e Áustria).

TABELA 1 - TAXA DE INOVAÇÃO PARA PAÍSES EUROPEUS E BRASIL, 2006

\begin{tabular}{|c|c|c|c|}
\hline País & $(\%)$ & País & $(\%)$ \\
\hline Alemanha & 62,6 & Eslovênia & 35,1 \\
\hline Bélgica & 52,2 & República Checa & 35,0 \\
\hline Finlândia & 51,4 & Itália & 34,6 \\
\hline Áustria & 50,6 & Espanha & 33,6 \\
\hline Luxemburgo & 48,5 & Brasil (2003-2005) & 33,4 \\
\hline Estônia & 48,2 & Turquia & 31,4 \\
\hline Irlanda & 47,2 & Croácia & 30,6 \\
\hline Dinamarca & 46,9 & Malta & 28,0 \\
\hline Suécia & 44,6 & Eslováquia & 24,9 \\
\hline Portugal & 41,3 & Polônia & 23,0 \\
\hline Grécia & 40,9 & Lituânia & 22,3 \\
\hline Chipre & 39,5 & Romênia & 20,7 \\
\hline Reino Unido & 38,1 & Lituânia & 20,2 \\
\hline Holanda & 35,5 & Hungria & 20,1 \\
\hline Noruega & 35,5 & Latívia & 16,2 \\
\hline
\end{tabular}

FONTE: Eurostat (2010), Community Innovation Statistics (2006) e PINTEC (2005).

O Brasil apresenta uma taxa de inovação semelhante às da Itália e Espanha. Cerca de um terço das empresas com mais de 10 empregados nesses três países realizou algum tipo de inovação no período analisado.

1 Os resultados mais recentes para o Brasil apontam para uma taxa de inovação de 38,1\% (PINTEC 2008, referente ao período 2006-2008). 
Esses novos indicadores têm representado um papel crucial na elaboração de políticas de inovação, pois permitiram entender melhor a realidade de cada país, o que não era captado de forma adequada pelos indicadores tradicionais relacionados às políticas de tecnologia (gastos em P\&D e patentes). Detalhes sobre os obstáculos à inovação, fontes de financiamento e diferenças entre inovação de produto e processo puderam ser explorados mais profundamente e ajudaram a moldar novos instrumentos de política de inovação.

\subsection{NOVAS TENDÊNCIAS}

O documento da OCDE (2010c), intitulado Innovation strategy: Getting a head start on tomorrow, representa talvez o reconhecimento mais importante de que a inovação não é apenas um fator importante para o crescimento econômico, mas também definidor dos rumos do futuro da economia e da solução de problemas globais.

Nesse documento são apresentadas diretrizes de políticas para a inovação e a proposta de uso de instrumentos de políticas que busquem criar ambientes favoráveis à inovação e ao empreendedorismo. Remoção de barreiras regulatórias (inclusive as administrativas) e o uso do poder de compra do governo são exemplos de mecanismos destacados. É interessante notar que tais instrumentos são menos dispendiosos que ajudas diretas às empresas e são destinados a "recompensar a inovação e a eficiência".

As diretrizes apresentadas estão na forma de cinco prioridades para a ação governamental (OCDE, 2010c, p. 11-15):

1. Deve ser dada às pessoas a capacidade de inovar: é reconhecido que o capital humano é a essência da inovação. Assim, é necessário reformular e adaptar currículos e práticas pedagógicas para que os estudantes possam aprender e desenvolver novas habilidades relacionadas às necessidades da sociedade. As universidades passam a ser reconhecidas como tendo papel fundamental no processo de inovação. É preciso também facilitar a mobilidade internacional de talentos para que o conhecimento circule;

2. Inovação nas firmas deve ser facilitada: são propostas várias medidas para encorajar o empreendedorismo. Por exemplo, é preciso tornar simples a regulação das firmas que entram no mercado, pois as firmas novas estão exercendo um papel cada vez mais importante na inovação. As leis de falência devem ser menos punitivas com os empreendedores. Empresas com rápido crescimento não devem ser "punidas" 
com maiores taxas de impostos ao se tornarem maiores. Acesso ao financiamento à inovação, como mercados de venture capital, deve ser desenvolvido;

3. A criação, a difusão e a aplicação do conbecimento são fundamentais: "A ciência continua a estar no coração da inovação". É reconhecido que as instituições de pesquisa de vários países da OCDE precisam se reestruturar para se manterem como centros de excelência. Além disso, a ligação com o setor produtivo deve ser aprimorada. As TIC são essenciais para a difusão do conhecimento e devem ser foco de atuação do governo a sua ampliação e acesso. Os direitos de propriedade intelectual geram incentivos para a criação de novas tecnologias e devem ser aplicados;

4. Inovação pode ser aplicada para tratar de desafios sociais e globais: esses desafios são caracterizados pela maior competição internacional, pelas pressões ambientais e pelo envelhecimento da população mundial. São globais não só porque afetam todos os países, independente da renda ou da localização, mas, talvez mais importante, por serem de uma escala tal que está acima da capacidade de qualquer país, requerendo uma cooperação para que sejam superados (OCDE, 2008). A cooperação científica e tecnológica internacional precisa ser facilitada e explorada. As incertezas envolvidas em questões como aquecimento global requerem que as iniciativas de inovação partam dos governos;

5. A governança e a mensuração das políticas de inovação devem ser aprimoradas: ao reconhecer que o processo de inovação envolve muitos atores, é necessário que o governo estabeleça novas formas de coordenação das ações.

Algumas dessas diretrizes refletem tendências observadas na última década, mas que tendem a nortear as políticas de inovação para a próxima.

Uma interessante análise sobre as tendências das políticas de inovação é apresentada por Borrás (2009). Segundo a autora, as políticas de vários países desenvolvidos e em desenvolvimento estão se tornando mais amplas e profundas.

Amplas no sentido de que o foco de ação das políticas de inovação está saindo do campo restrito do setor industrial e passando a considerar cada vez mais o setor de serviços. Outros temas também estão sendo objeto dessas políticas, como o uso da inovação para a redução da pobreza e melhoria da saúde e aprimoramento da segurança.

Por aprofundamento das políticas de inovação, Borrás entende que tem ocorrido a 
introdução de novos e mais sofisticados instrumentos de ação, o que permite aos governos buscar uma maior eficiência política.

Aos tradicionais instrumentos de política pública, ou seja, instrumentos regulatórios (normas para direitos de propriedade intelectual, regulação das universidades e institutos de pesquisa), econômicos e financeiros (incentivos fiscais e subsídios à $\mathrm{P} \& \mathrm{D}$, apoio à transferência de tecnologia, seed e venture capital) e suaves (informações, recomendações, adequação aos padrões internacionais), é adicionado um quarto instrumento ao lidar com a questão da inovação. A autora chama-o de "metainstrumentos", que tem o objetivo de prover inteligência à estrutura da política de inovação. Tais instrumentos são representados pelos indicadores, políticas de benchmarks e prospecção tecnológica.

Essas novas perspectivas têm sido motivadas por um melhor entendimento da inovação como tendo uma característica institucional, evolucionária e por ser um fenômeno econômico e social (BORRÁS, 2009, p. 4).

A seguir, são destacadas algumas das principais tendências verificadas nos documentos recentes da OCDE relativas às políticas de inovação para a próxima década (OCDE, 2009a, 2009b, 2010a, 2010b, 2010c).

\subsubsection{Aproximação entre academia e o mundo dos negócios}

Um dos marcos institucionais recentes na Europa foi a criação do European Institute of Innovation and Technology (EIT) em 2007 e com suas atividades iniciadas em 2008, que pretende ser "a key driver of sustainable European growth and competitiveness through the stimulation of world-leading innovations with a positive impact on economy and society"

A atuação do EIT está fundamentada no reconhecimento de que a Europa possui centros de excelência em educação superior e de pesquisa, mas que estão distantes do mundo dos negócios. A Europa poderia ter melhor desempenho inovativo se houvesse uma maior integração entre esses atores. Dessa forma, a União Europeia criou o EIT para ter como um dos seus objetivos o aprimoramento da ligação entre a academia, os centros de pesquisas e as empresas. A base para essa ligação serão as "Knowledge and Innovation Communities" (KICs) definidas ambiciosamente como "a highly integrated, creative and excellence-driven partnership which brings together the fields of education, technology, research, business and entrepreneurship, in order to produce new innovations and new innovation models that inspire others to emulate it".

Cada KIC é formada por dezenas de parceiros. As três primeiras KICs foram definidas para lidar com os seguintes temas: energia sustentável - KIC InnoEnergy; mudança climá-

2 Disponível em: <http://eit.europa.eu/about-eit/at-a-glance/eit-mission.html>. Acesso em: 10/2011. 
tica (mitigação e adaptação) - Climate KIC; e futura sociedade da informação e comunicação - EIT ICT Labs.

Essa tendência de dinamizar o caminho entre a pesquisa básica e a comercialização de novas tecnologias também acontece no nível nacional. Por exemplo, a Alemanha lançou em 2006 o programa High-Tech Strategy, envolvendo todos os ministérios e com a definição de estratégias para 17 "áreas de futuro". O objetivo do programa é "translating ideas from basic technologies as rapidly as possible into marketable products, services and processes" (OCDE, 2008, p. 120).

\subsubsection{Estímulo ao empreendedorismo}

Um dos instrumentos a serem utilizados pelo EIT para alavancar a inovação na Europa é o incentivo ao empreendedorismo. A atuação do EIT buscará criar um ambiente institucional que favoreça o surgimento de uma nova cultura empreendedora na Europa. Mais uma vez, o caso da Alemanha é emblemático, em que é reconhecido como desafio "to accompany innovation-specific policies with broader reforms that continue to lower regulatory and administrative barriers to entrepreneurship and to foster competition to further bolster the environment for innovative activity" (OCDE, 2008, p. 120, grifo nosso).

É possível perceber também uma preocupação em formar pessoas com qualificação para a transformação de conhecimento em negócios. Assim, adiciona-se ao treinamento em capacidades científicas e tecnológicas, a capacidade empreendedora.

\subsubsection{Instituições e governança para a inovação}

Vários países estão sinalizando para alterações nas regulamentações a fim de proporcionar um melhor ambiente para a inovação, como Reino Unido e Japão. No Japão por exemplo, " $[\mathrm{t}]$ he main policy challenge is to support innovative activities through continuing framework reforms. Improvements in public-private and international linkages and reduction of regulatory barriers to innovation will be particularly important" (OCDE, 2008, p. 132).

Estão surgindo também novas estruturas de governança para a inovação. Além do exemplo do EIT, a Coreia do Sul criou em 2008 o Ministério da Economia do Conhecimento, com vários objetivos, entre eles a promoção da conservação da energia, da segurança energética, do comércio eletrônico, da informatização, promoção do desenvolvimento, da transferência e da comercialização de tecnologias industriais, e o aprimoramento das capacidades de inovar das empresas.

O Reino Unido também criou o Departamento de Inovação, Universidades e Habili- 
dades, cuja função é promover "an integrated approach to the innovation challenges facing the country and for driving the government's long-term vision” (OCDE, 2008, p. 160). A França criou em 2005 a Agência para a Inovação Industrial (AII). Tal agência parte da constatação de que o setor industrial da França está composto, em grande medida, de indústrias de baixa intensidade tecnológica, sendo o foco atual o direcionamento para a promoção de indústrias de alta tecnologia (SUZIGAN; FURTADO, 2010).

\section{CONCLUSÃO}

Houve ao longo das cinco décadas de propostas de políticas pela OCDE uma mudança marcante. No início, foram estimuladas políticas para o fortalecimento da ciência e investimentos em P\&D. Nas décadas de 1980 e 1990 foram trazidas as questões sociais e ambientais para o discurso das políticas que passaram a considerar ciência e tecnologia (LUNDVALL; BORRÁS, 2005). Na última década a questão da inovação tornou-se o ponto-chave das políticas propostas pela OCDE.

Algumas políticas são reações às novas tendências no sentido de reforçá-las. Outras são reflexos claros de um maior entendimento do processo de inovação.

Entre as principais tendências destacadas nesse artigo estão:

- Busca de maior integração entre os agentes do sistema de inovação;

- Maior foco na promoção do empreendedorismo;

- Novas formas de governança das políticas de inovação;

· Ênfase na formação de talentos;

- Concentração de esforços para a superação de desafios globais.

\section{REFERÊNCIAS}

BORRÁS, S. The widening and deepening of innovation policy: what conditions provide for effective governance? CIRCLE Working Paper, n. 2, 2009.

EUROSTAT. Science, technology, and innovation in Europe. In: . EUROSTAT Statistical Books. Luxemburgo: EUROSTAT, 2010.

LUNDVALL, B.; BORRÁS, S. Science, technology, and innovation policy. In: FAGERBERG, J.; MOWERY, D.; NELSON, R. R. The Oxford handbook of innovation, Oxford: Oxford University Press, 2005.

OCDE. Science, technology and industry outlook. Paris: OECD, 2008. 
. Science, technology and industrial scoreboard. Paris: OECD, 2009a.

OECD reviews of innovation policy: Korea. Paris: OECD, 2009b.

. Measuring innovation: a new perspective. Paris: OECD, 2010a.

OECD factbook 2010: economic, environmental and social statistics. Science and technology. Paris: OECD, 2010b. 2010c.

The OECD innovation strategy: getting a head start on tomorrow. Paris: OECD,

SUZIGAN, W.; FURTADO, J. Instituições e políticas industriais e tecnológicas: reflexões a partir da experiência brasileira. Estudos Econômicos, v. 40, n. 1, p. 7-41, 2010. 